\title{
HLA: GENETIC CONTROL OF IMMUNE RESPONSE AND DISEASE SUSCEPTIBILITY
}

\author{
Takehiko SASAZUKI \\ Department of Human Genetics, Medical Research Institute, \\ Tokyo Medical and Dental University, Tokyo 113, Japan
}

Ever since the major histocompatibility complex (MHC)-linked immune response genes (Ir-genes) were described by McDevitt and Benacerraf in mice and guinea pigs (McDevitt and Chinitz, 1969; Benacerraf and McDevitt, 1972; McDevitt and Benacerraf, 1969), it has been widely assumed that the HLA linked Ir-genes or HLA-linked immune suppression genes ( $I s$-genes) exist in humans. Actually a series of studies on a statistical association between HLA and immune responses to particular antigens in vitro was reported (Greenberg et al., 1975; Spencer et al., 1976; de Vries et al., 1977; Sasazuki et al., 1978; Sasazuki et al., 1980a; Kato et al., 1978 ) suggesting the presence of the HLA-linked $I r$ - or $I s$-genes in man. This unproved hypothesis has been used by many investigators to explain the strong associations between HLA and diseases (Svejgaard et al., 1975; Dausset and Svejgaard, 1977; Sasazuki et al., 1977; McMichael and McDevitt, 1978).

The aim of this paper is to demonstrate the existence of the HLA-linked $I_{S-}$ gene and to show its crucial role in autoimmune disease and allergy in man.

Genetic control of immune response in man

Numerous attempts have been made to demonstrate the existence of $I r$-or $I s$ genes in man by using a series of antigens such as streptokinase and streptodornase (Greenberg et al., 1975), influenza A (Spencer et al., 1976), vaccinia (de Vries et al., 1977), tetanus toxoid (Sasazuki et al., 1978), schistosomal antigen (Sasazuki et al., 1980a), and rubella vaccine (Kato et al., 1978). All such studies demonstrated the statistical associations between HLA and immune responsiveness to these antigens, and Sasazuki et al. $(1978,1980$ a) first described the strong association between immune response and a particular antigen encoded for by the HLA-D region which is comparable to the murine $\mathrm{H}-2 \mathrm{I}$-region where $I r$ - and $I s$-genes were mapped (Dorf, 1981).

However, in order to identify the HLA-linked $I r$ - or $I s$-genes, family analysis was essential. Immune responsiveness to streptococcal cell wall (SCW) antigen was therefore investigated in 84 members of 18 helathy families. Forty-six members of another ten families were added to the analysis for correlation of immune response between siblings. The SCW antigen was purified from the type 12 streptococci strain Ss $95 / 12$ by a method described elsewhere (Sasazuki et al., 1980b). Immune 
response of the family members to the SCW antigen was determined by the antigen specific $T$ cell proliferation in vitro (Sasazuki et al., 1980b). Histogram for the distribution of the immune response of 84 family members to SCW antigen showed a clear bimodality, as is evident from analysis of the cumulative frequency distribution (Fig. 1). By these analyses the cut off point to divide the family members into high and low responders was determined at natural logarithm counts per minute$(\ln \mathrm{cpm})=9.6$. Segregation of the high and low responders to the SCW antigen assigned by this criterion among 18 families is summarized in Table 1 .

The mode of inheritance for the immune responsiveness to the SCW antigen was analyzed by the maximum likelihood scoring method (Morton, 1959) using the informative fourteen families. All of these families were completely ascertained and penetrance of the gene controlling immune responsiveness to the $\mathrm{SCW}$ antigen was assumed to be complete.

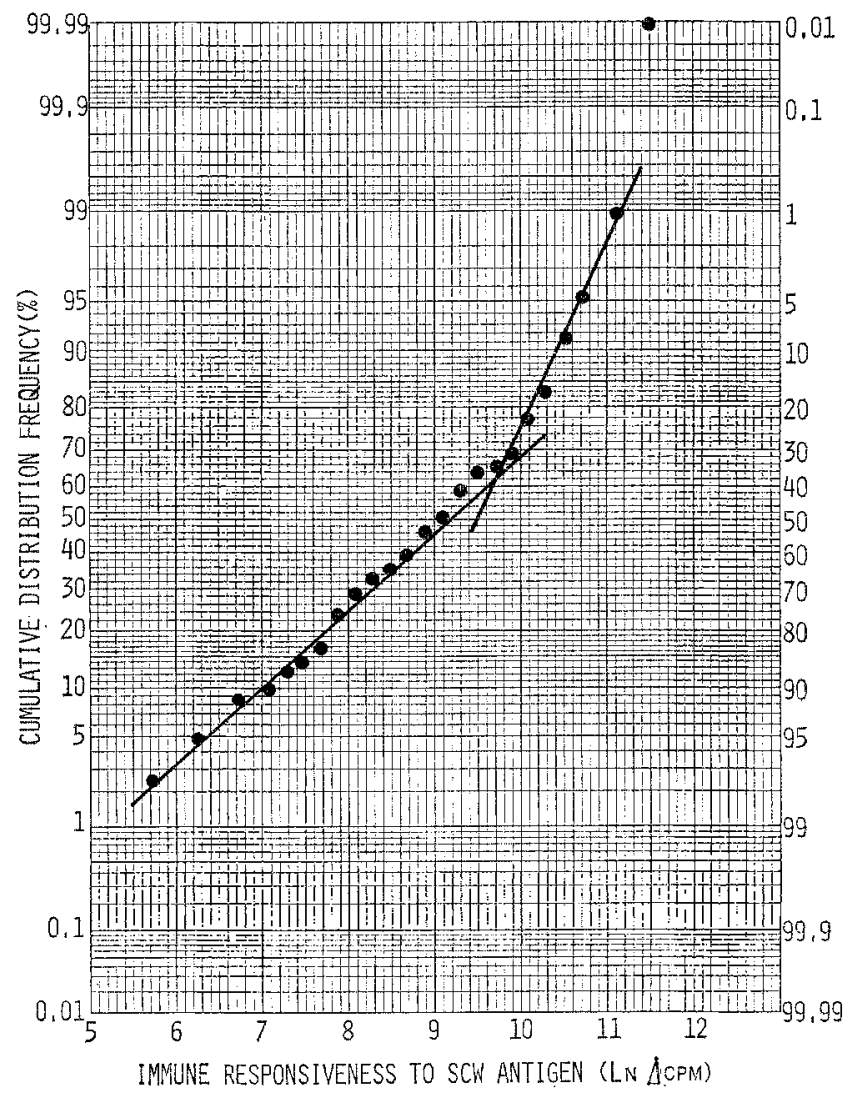

Fig. 1. Analysis of the distribution of the immune responsiveness to $\mathrm{SCW}$ antigen among family members. Abscissa indicates the classes of the immune responsiveness expressed by $\mathrm{In} \Delta \mathrm{cpm}$ and ordinate indicates the cumulative distribution frequency $(\%)$. Distribution can be divided into two groups with a mode around $\ln$ $\Delta \mathrm{cpm}=9.6$. 
Table 1. Summary of observed phenotypes for immune responsiveness to SCW antigen in 18 families. $H$ is high responder, and $\mathrm{L}$ is low responder.

\begin{tabular}{ccc}
\hline Phenotypes of parents & Phenotypes of children & Number of families \\
\hline $\mathrm{H} \times \mathrm{H}$ & $(\mathrm{H}, \mathrm{H})$ & 1 \\
\hline $\mathrm{H} \times \mathrm{L}$ & $(\mathrm{H})$ & 1 \\
& $(\mathrm{H}, \mathrm{H})$ & 1 \\
& $(\mathrm{H}, \mathrm{L})$ & 1 \\
& $(\mathrm{H}, \mathrm{H}, \mathrm{L})$ & 1 \\
& $(\mathrm{H}, \mathrm{L}, \mathrm{L})$ & 2 \\
& $(\mathrm{~L}, \mathrm{~L}, \mathrm{~L})$ & 1 \\
& $(\mathrm{H}, \mathrm{H}, \mathrm{H}, \mathrm{L})$ & 1 \\
& $(\mathrm{~L}, \mathrm{~L}, \mathrm{~L}, \mathrm{~L})$ & 3 \\
& $(\mathrm{H}, \mathrm{L})$ & 2 \\
& $(\mathrm{~L}, \mathrm{~L})$ & 1 \\
& $(\mathrm{~L}, \mathrm{~L}, \mathrm{~L})$ & 2 \\
\hline
\end{tabular}

The hypothesis that the low responsiveness is controlled by a single recessive gene should be discarded because many high responder children were segregated from the matings of low responders; moreover there was a significant difference between observation and expectation $(\mathrm{p}<0.05)$ in seven informative backcross families (Table 2). Six informative backcross families were then analyzed under the hypothesis of a single recessive gene for high responsiveness to the SCW antigen. There were no significant differences between observation and expectation in segregation of high responsiveness to the SCW antigen in these families $(p>0.45)$ indicating that the hypothesis of a single recessive gene for the high responsiveness to the SCW antigen probably can not be ignored (Table 3). This hypothesis also can not be discarded by the analysis of five informative intercross families $(p>0.37)$ (Table 4). All of these data support simple recessive inheritance for high responsiveness or simple dominant inheritance for low responsiveness to the SCW antigen in man.

One hundred and thirty family members of twenty-eight families were typed for HLA to investigate the correlation of immune responsiveness to the SCW antigen between siblings. The correlation of the phenotypes of immune responsiveness (high or low responsiveness) between HLA-identical siblings was complete (correlation coefficient $=1.0$ ). Those between HLA-haploidentical or nonidentical siblings were 0.59 or -0.46 respectively. The correlation for the immune responsiveness expressed by $\mathrm{ln} \mathrm{cpm}$ between HLA-identical siblings was very high $(\mathrm{r}=0.911, \mathrm{p}<$ 0.001 ) (Fig. 2), whereas that between HLA-haploidentical siblings was decreased to $0.460(p<0.01)$ (Fig. 3). There was no correlation at all between HLA-nonidentical 
Table 2. Analysis of the mode of inheritance for immune responsiveness to SCW antigen in vitro by the maximum likelihood scoring method of Morton, under the hypothesis of a single recessive gene for low responsiveness to SCW antigen in seven informative backcross families.

\begin{tabular}{ccccc}
\hline \multicolumn{5}{c}{ Backcross $(\mathrm{L} \times \mathrm{H})$} \\
\hline Sib size & $\begin{array}{c}\text { Number } \\
\text { of low } \\
\text { responders }\end{array}$ & Observed & Expected & $\chi^{2}$ \\
\hline 1 & 1 & 0 & 0 & 0 \\
2 & 1 & 1 & 0.67 & 0.17 \\
2 & 2 & 0 & 0.33 & 0.33 \\
3 & 1 & 1 & 1.71 & 0.30 \\
3 & 2 & 1 & 1.71 & 0.30 \\
3 & 3 & 2 & 0.57 & 3.57 \\
4 & 1 & 1 & 0.53 & 0.41 \\
4 & 2 & 0 & 0.80 & 0.80 \\
4 & 3 & 0 & 0.53 & 0.53 \\
4 & 4 & 1 & 0.13 & 5.63 \\
\hline Total & & 7 & 6.98 & 12.04 \\
& & & & p.F. $=5$ ) \\
\hline
\end{tabular}

Table 3. Analysis of the mode of inheritance for immune responsiveness to SCW antigen in vitro by the maximum likelihood scoring method of Morton, under the hypothesis of a single recessive gene for high responsiveness to $\mathrm{SCW}$ antigen in six informative backcross families.

\begin{tabular}{ccccc}
\hline & \multicolumn{5}{c}{ Backcross $(\mathrm{L} \times \mathrm{H})$} & \\
\hline Sib size & $\begin{array}{c}\text { Number } \\
\text { of high } \\
\text { responders }\end{array}$ & Observed & Expected & $\chi^{2}$ \\
\hline 1 & 1 & 1 & 1.00 & - \\
2 & 1 & 1 & 1.33 & 0.08 \\
2 & 2 & 1 & 0.67 & 0.17 \\
3 & 1 & 1 & 0.86 & 0.02 \\
3 & 2 & 1 & 0.86 & 0.02 \\
3 & 3 & 0 & 0.29 & 0.29 \\
4 & 1 & 0 & 0.27 & 0.27 \\
4 & 2 & 0 & 0.40 & 0.40 \\
4 & 3 & 1 & 0.27 & 2.02 \\
4 & 4 & 0 & 0.07 & 0.07 \\
\hline Total & & 6 & 6.02 & 3.34 \\
& & & & $(\mathrm{D} . \mathrm{F}=4)$ \\
& & 0.45 & 0.45 \\
\hline
\end{tabular}


Table 4. Analysis of the mode of inheritance for immune responsiveness to SCW antigen in vitro by the maximum likelihood scoring method of Morton, under the hypothesis of a single recessive gene for high responsiveness to SCW antigen in five informative intercross families.

\begin{tabular}{ccccc}
\hline \multicolumn{5}{c}{ Intercross $(\mathrm{L} \times \mathrm{L})$} \\
\hline Sib size & $\begin{array}{c}\text { Number } \\
\text { of high } \\
\text { responders }\end{array}$ & Observed & Expected & $\chi^{2}$ \\
\hline 1 & 1 & 0 & 0 & 0 \\
2 & 1 & 3 & 2.57 & 0.07 \\
2 & 2 & 0 & 0.43 & 0.43 \\
3 & 1 & 0 & 0 & 0 \\
3 & 2 & 0 & 0 & 0 \\
3 & 3 & 0 & 0 & 0 \\
4 & 1 & 2 & 1.23 & 0.48 \\
4 & 2 & 0 & 0.62 & 0.62 \\
4 & 3 & 0 & 0.14 & 0.14 \\
4 & 4 & 0 & 0.01 & 0.01 \\
\hline Total & & 5 & 5.00 & 1.75 \\
& & & & $(\mathrm{D} . \mathrm{F} .2)$ \\
\hline
\end{tabular}

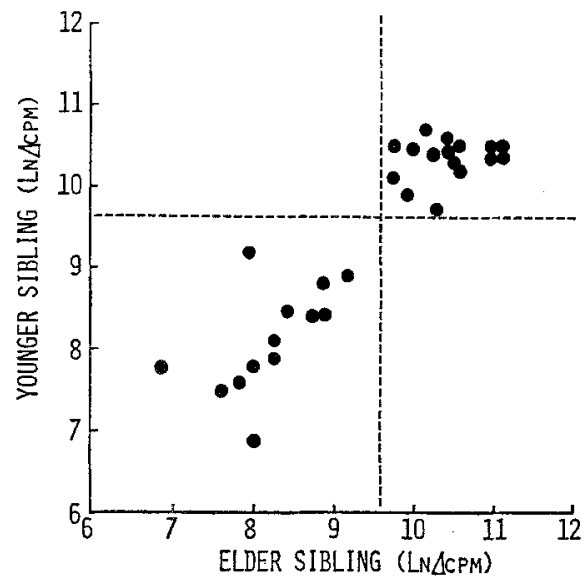

Fig. 2. Correlation of the immune response to SCW antigen between HLA-identical siblings. Abscissas is the in $\triangle \mathrm{cpm}$ of the elder sibling and the ordinate is that of the younger sibling. The dotted lines show the cut off point for low and high responsiveness. The correlation coefficient for immune responsiveness between HLA identical siblings, expressed by $\ln \Delta \mathrm{cpm}$, is $0.911(\mathrm{p}<0.001)$.

Vol. 27, No. 2, 1982 


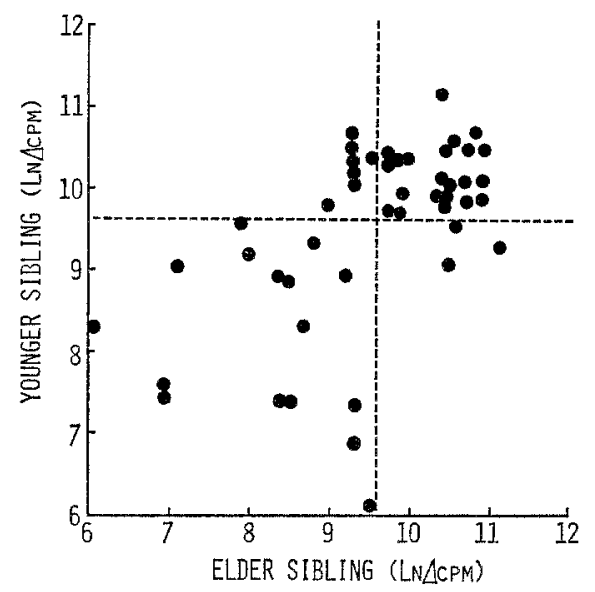

Fig. 3. Correlation of the immune response to SCW antigen between HLA-haploidentical siblings. The correlation coefficient for the immune responsiveness is 0.460 ( $p<$ 0.01).

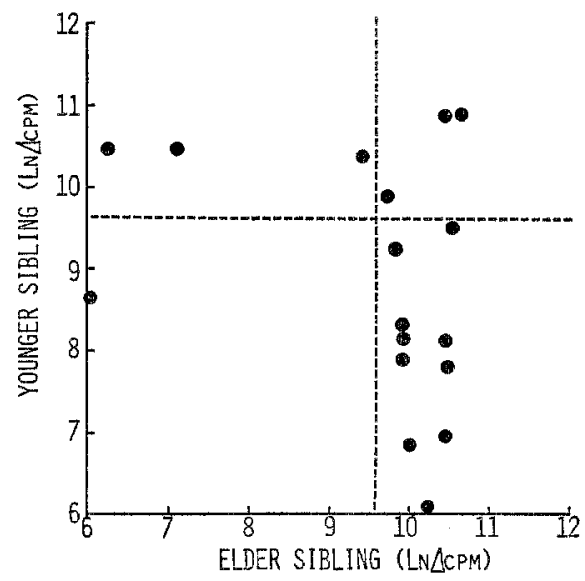

Fig. 4. Correlation of the immune response to SCW antigen between HLA-nonidentical siblings. The correlation coefficient for the immune responsiveness is -0.282 .

siblings $(r=-0.282)$ (Fig. 4). These observations indicate that HLA has a crucial role in controlling the immune responsiveness to the $\mathrm{SCW}$ antigen.

To test the linkage between HLA and immune responsiveness to the SCW antigen by Morton's sequential linkage test (Morton, 1957), four representative kindreds were examined for immune responsiveness to the SCW antigen and HLA genotypes (Pedigrees and data in Fig. 5). In each family, the low responders shared at least one specific HLA haplotype underlined in Fig. 5, which was not found in any of the high responders. This observation suggested that the dominant gene for low re- 


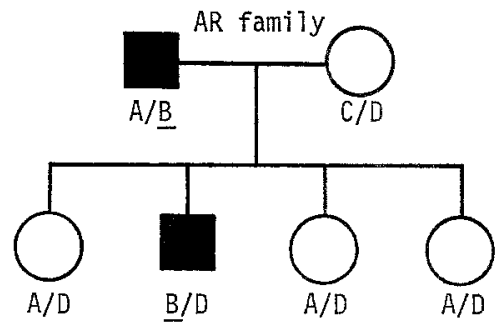

A: Aw24, Bw52, CW-, Dw12, DR2

B: $\mathrm{Aw} 33, \mathrm{Bw44}, \mathrm{CW}-, \quad$ DEn, DRw6

$C: A w 24, B w 51, C W_{-}, \quad D_{-}$, DR-

D: $A 26$, Bw46, Cw7, Cw3, D- , DRw6

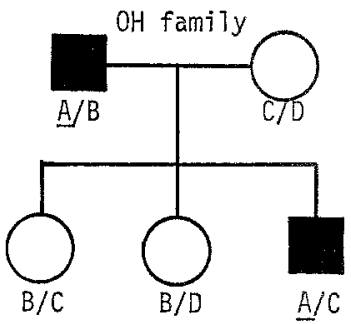

A: Aw24, Bw52, CW3, Dw72, DR2

$B: A W 24, B 13, C W 3, D-$, DR-

C: Aw24, Bw35, CW3, D- , DRw6

$D: A w 31, B 40, C w 3, D-$, DRw6

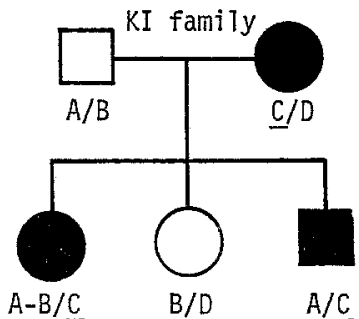

$A: A 2, B 40, C W 3, D R 4$

$B: A W 31, B W 51, C W-, D R 5$

C: $A 17, B W 54, C W 7, D R w 8$

$D: A 2, B w 54, C W 3, D R-$

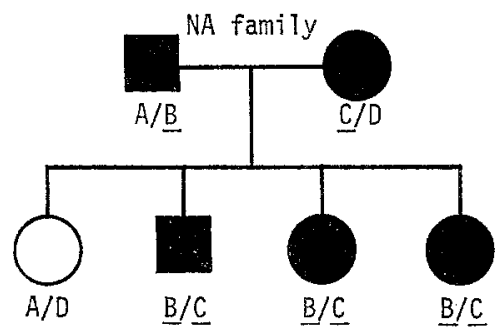

$A$ : Aw24, Bw35, CW3, DR-

B: AW24, BW51, CW-, DR4

C: $A w 24, B 7, C W-, D R]$

$D: A 11, B 15$, CW4, DR4

Fig. 5. Four representative pedigrees showing HLA genotypes and phenotypes of low or high immune responsiveness to SCW antigen. A, B, C and D are HLA haplotypes; $\square$ or $O$, high responders; and - or low responders. In each family, low responders shared an HLA haplotype which was not shared by high responders and are underlined.

Table 5. Lod score for linkage between HLA and low responsiveness to SCW antigen calculated from nine informative families by Morton's sequential linkage tests.

\begin{tabular}{lllllll}
\hline & \multicolumn{7}{c}{ Recombination fraction $(\theta)$} \\
\cline { 2 - 7 } Family & 0.00 & 0.01 & 0.02 & 0.03 & 0.04 & 0.05 \\
\hline KA & 0.125 & 0.116 & 0.108 & 0.100 & 0.093 & 0.086 \\
YA & 0.125 & 0.116 & 0.108 & 0.100 & 0.093 & 0.086 \\
KO & 0.301 & 0.292 & 0.284 & 0.275 & 0.266 & 0.258 \\
SO & 0.301 & 0.292 & 0.284 & 0.275 & 0.266 & 0.258 \\
NA & 0.375 & 0.374 & 0.373 & 0.371 & 0.368 & 0.365 \\
HA & 0.375 & 0.374 & 0.373 & 0.371 & 0.468 & 0.365 \\
KI & 0.602 & 0.589 & 0.576 & 0.562 & 0.549 & 0.535 \\
OH & 0.602 & 0.589 & 0.576 & 0.562 & 0.549 & 0.535 \\
AR & 0.903 & 0.886 & 0.868 & 0.850 & 0.832 & 0.814 \\
\hline Total & 3.709 & 3.628 & 3.550 & 3.466 & 3.384 & 3.302 \\
\hline
\end{tabular}


sponsiveness to the SCW antigen was linked to HLA haplotypes shared by the low responders. A maximum lod score (3.709) was obtained at $0=0.00$ (Table 5) showing very close linkage between HLA and low responsiveness to the SCW antigen. Thus an HLA-linked gene controlling low responsiveness to SCW antigen was identified.

By analyzing immune response to measeles, streptococcal antigen or synthetic polypeptide chain, ( $T, G)-A--L$, in families, three groups claimed the existence of HLA-linked Ir-genes (Haverkorn et al., 1975; Greenberg et al., 1980; Hsu et al., 1981) which controlled high responsiveness to those antigens. None of the groups, however, studied the cellular mechanisms of those genetic regulations.

Immune response of peripheral blood lymphocytes to the SCW antigen is monocyte dependent $T$ cell proliferation. Recently we have noted the existence of genetic restriction by HLA-DR antigen but not by HLA-D nor by HLA-DR supertypic (MT) antigen of the cooperative interaction between $\mathrm{T}$ cells and monocytes in the immune response to the SCW antigen in vitro. T cells from high responders exhibited a proliferative response with monocytes from low responders but $T$ cells from low responders failed respond even in the presence of monocytes from high responders which shared at least one HLA-DR antigen with $T$ cell donor. This may be taken to indicate that the gene controlling low responsiveness to the SCW antigen was expressed at the $\mathrm{T}$ cell level but not at the monocyte level. Furthermore we observed by using anti-human $T$ cell monoclonal antibodies that the proliferative response to the SCW antigen was carried by the Leu-2a negative, Leu-3a positive helper $T$ cells, and low responders have the Leu-2a positive, Leu-3a negative suppressor $T$ cells which suppressed the proliferative response of autologous, HLADR identical, or HLA-DR haploidentical helper $\mathrm{T}$ cells from high responders (unpublished observation). The single dominant gene for low responsiveness to the SCW antigen is, therefore, analogous to the murine immune suppression gene which controls the low responsiveness by inducing suppressor T cells (Debré et al., 1975; Benacerraf and Dorf, 1977). It is conceivable that these $I s$-genes contribute to the normal state of tolerance to self-antigen or many allergens. If so, the absence of such genes in the homozygous individuals may predispose to immune related diseases such as autoimmune diseases and allergy.

\section{Genetic control of disease susceptibility}

There has been an accumulation of evidence showing that genes in the HLA system have a makred effect on susceptibility to a wide variety of diseases (Svejgaard et al., 1975; Dausset and Svejgaard, 1977; Sasazuki et al., 1977; McMichael and McDevitt, 1978). Most of the studies were, however, done at the population level, and family analysis is again indispensable for identifying the disease susceptibility genes.

Multiplex family with Graves' disease was analysed by the sib-pair method described by Penrose (1935). The disease-associated haplotypes of HLA and im- 
munoglobulin allotypes $(\mathrm{Gm})$ were identified in each family by determining the haplotypes shared by two affected siblings (Uno et al., 1981). The aim was to determine if all the affected siblings shared the disease-associated haplotypes of both HLA and Gm. One affected sibling used to determine the disease-associated haplotypes of HLA and $\mathrm{Gm}$ in each family was excluded from the calculation.

All affected siblings in 14 families with Graves' disease shared the disease-associated haplotypes of HLA and Gm. However, siblings who shared the diseaseassociated haplotypes did not necessarily suffer from the disease (Fig. 6). This genetic association between the development of Graves' disease and particular HLA and $\mathrm{Gm}$ haplotypes in each family was statistically significant $\left(\mathrm{p}<6.0 \times 10^{-4}\right)$ (Table 6). The association was strong and significant in female siblings $\left(p<6.0 \times 10^{-4}\right)$,

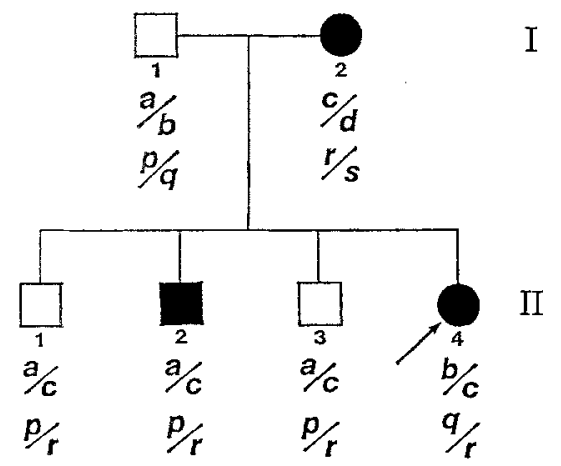

Fig. 6. A family affected with Graves' disease. - $\mathbf{n}$, Graves' disease. a, HLA-A26, Bw54, Cwl; b, HLA-A2, Bw54, —; c, HLA-A11, Bw39, —; d, HLA-A2, —, 一; p, $\operatorname{Gm}(1,13,15,16,17) ; \mathrm{q}, \operatorname{Gm}(1,17,21) ; \mathrm{r}, \mathrm{Gm}(1,3,5,13,23) ; \mathrm{s}, \mathrm{Gm}(1,13$, $15,16,17)$.

Table 6. Association between Graves' disease and HLA- and Gm-haplotypes in 14 informative families.

\begin{tabular}{|c|c|c|c|c|}
\hline & & \multicolumn{2}{|c|}{$\begin{array}{l}\text { Disease-associated haplotypes } \\
\text { of HLA and Gm allotype }\end{array}$} & \multirow{2}{*}{$\mathrm{P}$} \\
\hline & & Positive a & Negative $b$ & \\
\hline \multirow[t]{2}{*}{ Total sib $(n=43)$} & Affected & 16 & 0 & \multirow{2}{*}{$<6.0 \times 10^{-4}$} \\
\hline & Unaffected & 14 & 13 & \\
\hline \multirow{2}{*}{ Female sib $(n=32)$} & Affected & 13 & 0 & \multirow{2}{*}{$<6.0 \times 10^{-4}$} \\
\hline & Unaffected & 8 & 11 & \\
\hline \multirow[t]{2}{*}{ Male sib $(n=11)$} & Affected & 3 & 0 & \multirow{2}{*}{ NS } \\
\hline & Unaffected & 6 & 2 & \\
\hline
\end{tabular}

One affected sibling used to determine disease-associated haplotypes in each family was excluded from this analysis. The $\mathbf{P}$ value was calculated by Fisher's exact method.

NS, not significant. a Positive for disease-associated HLA and Gm haplotypes. b Negative for either or both disease-associated HLA haplotype and Gm haplotype. 
but not significant in male siblings, probably due to the small number of male patients in these families. The strong association between the development of Graves' disease and HLA and Gm haplotypes indicated that there might be two genes linked to HLA and Gm, respectively, which had major effects on the development of Graves' disease. Fourteen siblings who had the disease-associated haplotypes were from 12 to 49 year old (mean age 27.6 year). Because the age of onset of Graves' disease varies widely, they may possibly develop the disease later in life.

Mode of inheritance and gene frequency of the HLA-linked disease susceptibility gene was inferred by using the affected sib-pair method developed and utilized by Cudworth et al. (1975), Day and Simons (1976), Thomsen and Bodmer (1977) and Svejgaard and Ryder (1981).

Fifteen affected sibpairs could be unequivocally assigned as sharing either 2 or 1 HLA haplotypes identical by descent. Out of 15 affected sibpairs 8 shared 2 HLA haplotypes and 7 shared 1 HLA haplotype which differed significantly from the random ratio $(1: 2: 1$ for sharing 2,1 or 0$)(p<0.025)$ (Table 7). Analysis of haplotype distribution of affected sibpairs showed that the minimum chi square for the recessive model was 1.39 with a frequency of the HLA-linked gene of 0.30 an indication that we can not exclude the recessive model. An even lower chi square $(0.07)$ was obtained for the dominant model with the frequency of HLA-linked gene 0.00 . The frequency 0.00 for a disease susceptibility gene does not make sense, but we can obtain an appreciable gene frequency $(0.08)$ under the dominant model at a chi square $=1.34$, which was comparable to the minimum chi square for the recessive model. At this stage, given the small sample size $(n=15)$, it is not possible to rule out the dominant model simply because the minimum chi square was obtained at a gene frequency $=0.00$ (Sasazuki et al., 1982). However, the dominant model was clearly rejected if the current data were analyzed together with those of Farid and Bear (1982) of 43 affected sib-pairs, 27 shared two, 14 shared one and two shared zero HLA haplotypes (Fig. 7). It was thus possible to identify the HLA-linked recessive gene which has a major effect on the development of Graves' disease.

Tabie 7. Tests for genetic hypotheses of Graves' disease based on HLA haplotype assortment data.

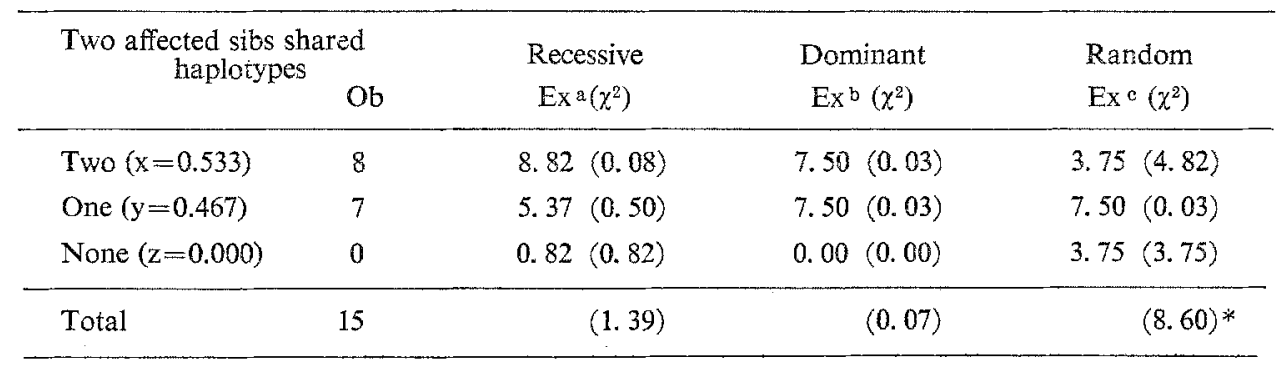

$* 0.01<\mathrm{p}<0.025$.

a Based on an estimated gene frequency of $0.30 \pm 0.10$. b Based on a gene frequency 0.00 estimated by maximum likelihood. $c$ Based on random ratio $1: 2: 1$. 


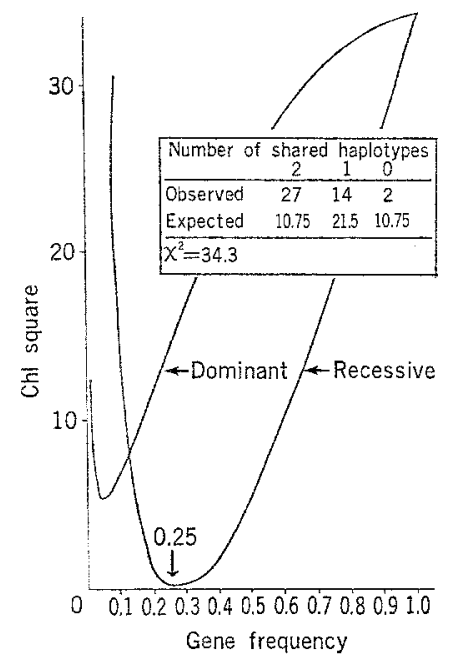

Fig. 7. Inference of mode of inheritance and gene frequency for Graves' disease by affected sib-pair method.

Table 8. Association between Graves' disease and HLA.

\begin{tabular}{cccccc}
\hline HLA-antigens & $\begin{array}{c}\text { Graves' } \\
\text { disease } \\
(\mathrm{n}=30)\end{array}$ & $\begin{array}{c}\text { Control } \\
\text { group } \\
(\mathrm{n}=80)\end{array}$ & Chi-square & Pc & RR \\
\hline DR5 & $9(30.0 \%)$ & $4(5.0 \%)$ & 13.08 & $<3.0 \times 10^{-3}$ & 8.14 \\
DRw8 & $11(36.7 \%)$ & $13(16.3 \%)$ & 5.82 & NS & 3.07 \\
\hline
\end{tabular}

DR5 and DRw8 were determined using 11 and 5 sera, respectively, from the 8 th International Histocompatibility Workshop.

Pc: P multiplied by the number of HLA-DR antigens studied, RR: relative risk. NS: not significant.

In a study of 30 unrelated probands in these families with Graves' disease, the antigen frequency of HLA-DR5 was significantly increased to $30.0 \%$ ( 9 out of 30 ), compared with $5.0 \%$ ( 4 out of 80 ) in a control group $\left(\mathrm{p}<3.0 \times 10^{-3}\right.$, relative risk $=$ 8.14) (Table 8). The association between Graves' disease and HLA-DR5 implied that the HLA-linked disease susceptibility gene was in strong linkage disequilibrium with HLA-DR5. There was, on the other hand, no significant association between Graves' disease and any particular immunoglobulin allotype in these probands, suggesting the absence of significant linkage disequilibrium between $\mathrm{Gm}$ and the Gm-linked disease susceptibility gene.

Two loci plus environmental factors involved in disease was also proposed by Thomson (1980) to explain the genetic mechanism of juvenile onset insulin dependent diabetes mellitus, even though they could not identify the second locus by any 
specific genetic markers. In Graves' disease, the two locus model was verified by the clear demonstration of the closely linked loci, HLA or Gm, for each locus.

What would be the disease susceptibility genes linked to HLA-DR and Gm? The HLA-D region is assumed to be comparable to the I-region of the murine $\mathrm{H}-2$ complex, in which immune response genes ( $\mathrm{Ir}$-genes) and immune suppression genes (Is-genes) are mapped. As mentioned earlier an HLA-linked $I s$-gene which controls the low or non-responsiveness to the streptococcal cell wall (SCW) antigen in vitro was clearly demonstrated in man. In this situation, the high responsiveness to the SCW antigen is a recessive trait. Since the HLA-linked disease susceptibility locus for Graves' disease seems to be recessive, an HLA-linked $I s$-gene controlling the high immune responsiveness of the recessive homozygous state is an attractive candidate for the gene. Indeed an HLA-linked $I s$-gene was proposed to be the best candidate for the HLA-linked recessive locus which was identified by the family analysis including the affected sib-pair method and sequential linkage test in ceder pollenosis (allergy to the ceder pollen antigens). The patients with ceder pollenosis produced IgE antibody to the ceder pollen antigens whereas the healthy family members did not respond to the antigen. The low responsiveness to ceder pollen antigen is a dominant trait controlled by an HLA-linked Is-gene which governs the generation of suppressor $\mathrm{T}$ cells. In the case of allergy it was thus possible to conclude that the HLA-linked $I s$-gene is the disease susceptibility gene because the antigen directly involved in the pathogenesis of allergy is well characterized. In similar way the elucidation of the antigen(s), the environmental factor(s), involved in the pathogenesis of Graves' disease will, in turn, make it possible to identify the HLA-linked $I s$-gene controlling the susceptibility to Graves' disease.

It is, thus, evident that HLA governs the susceptibility to certain diseases by controlling the immune responsiveness to particular antigens.

Acknowledgements I wish to express my thanks to Dr. Haward Hamilton (Radiation Effects Research Foundation) for his comments on the manuscript.

This work was supported by the Research Grant (No. 548145, 1981) from the Ministry of Education, Science and Culture of Japan, the Research Grant for the Intractable Diseases from the Ministry of Health and Welfare of Japan 1981, The Naito Foundation 1981 and The Mitsubishi Foundation 1981.

\section{REFERENCES}

Benacerraf, B., and Dorf, M.E. 1977. Genetic control of specific immune responses and immune suppression by I-region genes. Cold Spring Harbor Symp. Quant. Biol. 41: 465-475.

Benacerraf, B., and McDevitt, H.O. 1972. Histocompatibility-linked immune response genes. Science 175: 273-279.

Cudworth, A.G., and Woodrow, J.C. 1975. Evidence for HLA-linked genes in "juvenile" diabetes mellitus. Brit. Med. J. iii: 133-135.

Dausset, J., and Svejgaard, A. 1977. HLA and Disease (entire volume). Munksgaard, Copenhagen.

Day, N.E., and Simons, M.J. 1976. Disease susceptibility genes-Their identification by multiple case family studies. Tissue Antigens 8: 109-119. 
Debre, P., Kapp, J.A., Dorf, M.E., and Benacerraf, B. 1975. Genetic control of specific immune suppression. II. H-2 linked dominant genetic control of immune suppression by the random copolymer L-glutamic acid ${ }^{50}-$ L-tyrosine (GT). J. Exp. Med. 142: 1447-1454.

de Vries, R.R.P., Kreeftenberg, H.G., Loggen, H.G., and van Rood, J.J. 1977. in vitro immune responsiveness to vaccinia virus and HLA. N. Engl. J. Med. 197: 692-696.

Dorf, M.E. 1981. Genetic control of immune responsiveness. In The Role of the Major Histo compatibility Complex in Immunobiology, Dorf, M.E. ed., Garland, New York, pp. 221-254.

Farid, N.R., and Bear, J.C. 1982. In Autoimmune Endocrine Disease. Wiley, New York, in press.

Greenberg, L.J., Gray, E.D., and Yunis, E.J. 1975. Association of HL-A5 and immune responsiveness in vitro to streptococcal antigens. J. Exp. Med. 141: 935-543.

Greenberg, L.J., Bradley, P.W., Chopyk, R.L., and Lalovel, J.M. 1980. Immunogenetics of response to a purified antigen from group A streptococci. II. Linkage of response to HLA. Immunogenetics 11: 161-167.

Haverkorn, M.J., Hofman, B., Masurel, N., and van Rood, J.J. 1975. HLA-linked genetic control of immune response in man. Transplant. Rev. 22: 120-124.

Hsu, S.H., Chan, M.M., and Bias, W.B. 1981. Genetic control of major histocompatibility complex-linked immune responses to synthetic polypeptides in man. Proc. Natl. Acad. Sci. USA. 78: 440-444.

Kato, S., Kimura, M., Takakura, I., Sakakibara, T., Inoue, H., and Tsuji, K. 1978. Possible associations between HLA antigens and the immune responsiveness to attenuated rubella vaccine. Tissue Antigens 11: 475-478.

McDevitt, H.O., and Benacerraf, B. 1969. Genetic control of specific immune responses. $A d v$. Immunol. 11: 31-74.

McDevitt, H.O., and Chinitz, A. 1969. Genetic control of antibody response: relationship between immune response and histocompatibility (H-2) type. Science 163: 1207-1209.

McMichael, A., and McDevitt, H.O. 1977. The association between the HLA system and disease. Prog. Med. Genet. 2: 39-100.

Morton, N.E. 1957. Further scoring types in sequential linkage tests, with a critical review of autosomal and partial sex linkage in man. Am. J. Hum. Genet. 9: 55-75.

Morton, N.E. 1959. Genetic tests under incomplete ascertainment. Am. J. Hum. Genet. 11: 1-16.

Penrose, L.S. 1935. The detection of autosomal linkage in data which consist of pairs of brothers and sisters of unspecified parentage. Ann. Eugen. 6: 133-138.

Sasazuki, T., Grumet, F.C., and McDevitt, H.O. 1977. The association between genes in the major histocompatibility complex and disease susceptibility. Annu. Rev. Med. 28: 425-452

Sasazuki, T., Kohno, Y., Iwamoto, I., Tanimura, M., and Naito, S. 1978. Association between an HLA haplotype and low responsiveness to tetranus toxoid in man. Nature 273: 359-360

Sasazuki, T., Ohta, N., Kaneoka, R., and Kojima, S. 1980a. Association between an HLA haplotype and low responsiveness to schistosomal worm antigen in man. J. Exp. Med. 152: 314s$318 \mathrm{~s}$.

Sasazuki, T., Kaneoka, H., Nishimura, Y., Kaneoka, R., Hayama, M., and Ohkuni, H. 1980 b. An HLA-linked immune suppression gene in man. J. Exp. Med. 152: 297s-313s.

Sasazuki, T., Uno, H., Yasuda, N., Tamai, H., and Matsumoto, H. 1982. Evidence for HLAlinked, and Gm-linked genes in Graves' disease. In 6th Int. Cong. Hum. Genet. Vol. 2, Liss, New York, in press.

Spencer, M.J., Cherry, J.D., and Terasaki, P. 1976. HLA antigens and antibody response after influenza A vaccination. Decreased response associated with HLA type W16. N. Engl. J. Med. 294: 13-16.

Svejgaard, A., Hauge, M., Jersild, C., Platz, P., Ryder, L.P., Staub-Nielsen, L., and Thomsen, M. 1975. The HLA system. Monographs in Human Genetics 7.

Svejgaard, A., and Ryder, L.P. 1981. HLA genotype distribution and genetic models of insulin-dependent diabetes mellitus. Ann. Hum. Genet. 45: 293-298 
Thomson, G. 1980. A two locus model for juvenile diabetes. Ann. Hum. Genet. 43: $383-398$

Thomson, G., and Bodmer, W.F. 1977. The genetics of HLA and disease associations. In Measuring Selection in National Populations, Christiansen, T.B., and Feachel, T.M, eds., Springer-Verlag, Berlin, pp. 545-564.

Uno, H., Sasazuki, T., Tamai, H., and Matsumoto, H. 1981. Two major genes, linked to HLA and Gm, control susceptibility to Graves' disease. Nature 292: 768-770 